\title{
Awareness of Hypertension, Risk Factors and Complications among Attendants of a Primary Health Care Center In Jeddah, Saudi Arabia
}

\author{
Abeer Hazaa, MD. ${ }^{1}$ \\ ${ }^{I}$ General Practitioner, Al-Harzat Primary Health Care Centre- Jeddah - Saudi Arabia
}

\begin{abstract}
:
Background:Hypertension is one of the most common communicable chronic diseases affecting people worldwide. Hypertension is also a major risk factor for cardiac diseases specially coronary and ischemic heart diseases as well as hemorrhagic stroke. the prevalence of hypertension in Kingdom of Saudi Arabia is about $26.1 \%$.

Aim and objectives: Estimate the prevalence of hypertension and to determine the level of awareness with regards to risk factors, presenting features and complications of hypertension among a sample from Jeddah population, Saudi Arabia.

Methods: An observationaldescriptive cross sectional study conducted in a Primary Health Care Center located in Jeddah city using a pretested self-administered questionnaire.

Results: Among the 200 participants prevalence of $26 \%$ and $12 \%$ were recorded for diabetes mellitus and hypertension, respectively

$\%$. Seventy percent of our study participants are having family members complaining from diabetes and hypertension.

Although self evaluation regarding knowledge of hypertension was low, it was found that the percent of correct answers received was satisfactory.

Conclusion: we can conclude that diabetes and hypertension are considered a burden among the Saudi Community. Health education program are satisfactory, recommendation for more in-depth studies for assessing the strategies and was of delivery may be recommended.
\end{abstract}

\section{Introduction}

Hypertension is one of the most common communicable chronic diseases affecting people worldwide. We can define hypertension as persistent elevation of systolic Blood Pressure (SBP) $\geq 140 \mathrm{~mm} \mathrm{Hg}$ and/or Diastolic Blood Pressure (DBP) $\geq 90 \mathrm{~mm}$ Hg provided that at least two readings were recorded on two separate occasions in adults not on antihypertensive medications[1]. Hypertension is also a major risk factor for cardiac diseases specially coronary and ischemic heart diseases as well as hemorrhagic stroke [2]. Worldwide, it is estimated to cause 7.5 million deaths, about $12.8 \%$ of the total of all deaths [2]. It is projected in year 2025 to increase by $24 \%$ in developed countries and $80 \%$ in developing countries [3]. Hypertension is an extremely common comorbid condition in diabetes, affecting $20-60 \%$ of patients with diabetes, depending on obesity, ethnicity, and age. In type 2 diabetes, hypertension is usually present as component of the metabolic syndrome of insulin resistance also including waist obesity and hyperlipidemia. In type 1 diabetes, hypertension may play a role regarding the onset of diabetic nephropathy. Hypertension essentially increases the risk of both macrovascular and microvascular complications, including cerebral stroke, coronary artery disease, and peripheral vascular disease, retinopathy, nephropathy, and possibly neuropathy. recently, many dataobtained from randomized clinical trials have demonstrated the effectiveness of aggressive treatment of hypertension in reducing both types of diabetes complications[4].

A study on about 17,230 of Saudi population showed that the prevalence of hypertension in Kingdom of Saudi Arabia is about $26.1 \%$ [5]. National surveys of prevalence, awareness, treatment, and control provide basis for assessing the burden of hypertension in the community. These surveys showed that many hypertensives were unaware of their disease, many of the aware were not on treatment, and many of the treated are not controlled particularly in developing countries [5]. The increasing prevalence of hypertension is attributable to rapid transition of life style practices in developing countries as well as increased elderly population due to an increase in life expectancy[2,5].

Very few studies have been carried out on prevalence of hypertension and awareness of its risk factors and complications among Jeddah population with sufficient sample size. Therefore, the present study was undertaken with the objective to estimate the prevalence of HTN and to determine the level of awareness with 
Awareness of Hypertension, risk factors and complications among attendants of a Primary Health ..

regards to risk factors, presenting features and complications of hypertension among a sample from Jeddah population, Saudi Arabia.

\section{Methodology}

This study isan observationaldescriptive cross sectional study conducted in a Primary Health Care Center located in Jeddah city representing one of the Saudi Cities in order to measure the awareness of hypertension risk factors and complications among clients attending the Primary Health care center.

The target population consisted of females and males at different ages from Jeddah community coming for any reason to the Primary health care center.

\section{Inclusion criteria:}

1- Patients coming to Primary health care for any reason

2- Patients who were newly diagnosed with hypertension

3- Adult above 18 years of age.

4- Resident in Jeddah City

Exclusion criteria: people who less than 18 years of age.

Over a period of three months a systematic random sample will be applied 3 days a week to include a convenient sample.

A self-administered questionnaire in addition to measurements of blood pressure, height and weight (BMI), lipid profile (HDL, TGA), random Blood Glucose (RBG) for all participants. Blood pressure will be measured using both mercury Sphygmomanometer.

Each participant will fill up a questionnaire after signing an informed consent. The questions focused on how much the participant knows about hypertension,itsrisk factors and complications. For those who will voluntary accept Random Blood sugar (RBS), Blood pressure (BP) and Body mass index (BMI) will be measured.Each participant will sit on a comfortable chair and blood pressure will be measured after 5 minutes to ensure that he/she is relaxed. The cuff of sphygmomanometer will be placed on the arm, taking into consideration that the cubital fossa is free, and it was kept at the level of the heart.

\section{Data Management and Analysis plan:}

Statistical evaluation of all data will be done using SPSS software for windows (Statistical Package for Social Sciences version 23, USA) and excels for figures. "Categorical variables will be described using proportions (percentages)". All tests were two tailed and considered significant when $\mathrm{p}<0.05$.

\section{Ethical considerations:}

This study will be submitted to the ethics Committee of Taibah University College of Dentistry and all participating patients will sign an informed consent.

\section{Results}

The total number of participants in this study over a period of three months of recruitment was 200 Participants. Saudi nationals represented 90\% (180/200) however non Saudi represented only 10\% (20/200).

The mean age was $38.94 \pm 8.713$. For those who smoke cigarettes the average number of cigarettes smoked per day was $13 \pm 7.4$

Body Mass index of the studied group was, $29.009 \pm 5.86$.

The means systolic BP was $121.69 \pm 15.2$ and the means diastolic BP was 66.714 \pm 9.5. Random Blood sugar (RBS) $111.445 \pm 61.59$. Median RBS was 100, the highest recorded value was 265 .

Females were the majority $172 / 200(86 \%)$ compared to males $28 / 200(14 \%)$.

Table 1 shows the sociodemographic characteristics of the study population. It was noted that University and post graduate level represented $48 \%$ of the study sample. Regarding the family income, it was obvious that only $14 \%$ of the study sample are having a monthly income less than $3000 \mathrm{SR} /$ month.

As shown from Table 2, 70\% (140/200) of our study participants are having family members complaining from diabetes and hypertension.

Table 3; shows the health habits of the study participants regarding fast food consumption, practicing sports smoking cigarettes and shisha. Interestingly it was shown in this table that $12 \%$ smoke shisha and only $6 \%$ smoke cigarettes.

It was found that 56 study participants was on diet prescribed by a health care professional. Hypertension represented a main cause of being on diet for 20/200 (10\%) participants, High Cholesterol represented 28/200 (14\%), Diabetes mellitus represented 32/200 (16\%), Obesity represented 40/200 (20\%) of participants, however being on diet for improving of health represented 64/200 (32\%). 
Awareness of Hypertension, risk factors and complications among attendants of a Primary Health ..

For our study participants table 4 shows that the prevalence of Diabetes is $26 \%$, Hypertension $12 \%$, Coronary heart disease $4 \%$, High cholesterol $18 \%$ and those who are on regular medications represents $28 \%$.

Table 5 demonstrate the knowledge regarding Hypertension in term of the self evaluation, normal values of blood pressure risk factors, protective factors and organ that can be affected. In General it was noticed that the level of knowledge is accepted regarding most variables despite of the response toward self evaluation regarding the level of knowledge regarding hypertension which was found to be $32 \%$ who classified their knowledge as accepted and well(12\% and $20 \%$ respectively).

Table 1: Sociodemographic characteristics of the study population

\begin{tabular}{|l|l|l|}
\hline Items & $\begin{array}{l}\text { Frequency } \\
\text { N=200 }\end{array}$ & \% \\
\hline Marital Status & 4 & 2 \\
\hline Divorced & 172 & 86 \\
\hline Married & 24 & 12 \\
\hline Single & & \\
\hline Employment & 24 & 12 \\
\hline Educational sector & 28 & 14 \\
\hline Health Sector & 24 & 12 \\
\hline Others & 16 & 8 \\
\hline Student & 104 & 52 \\
\hline Unemployed & 4 & 2 \\
\hline Worker & & \\
\hline Educational level & 44 & 22 \\
\hline Illiterate & 32 & 16 \\
\hline Primary & 4 & 2 \\
\hline Intermediate & 24 & 12 \\
\hline Secondary & 60 & 30 \\
\hline University & 36 & 18 \\
\hline Post graduate & & \\
\hline Monthly Income & 28 & 14 \\
\hline Less than 3000SR & 104 & 52 \\
\hline 3000-6000 SR & 24 & 12 \\
\hline 6000-9000 SR & 44 & 22 \\
\hline More than 9000SR & & \\
\hline
\end{tabular}

Table 2: Family Chronic Disease History

\begin{tabular}{|l|l|l|}
\hline Disease & $\begin{array}{l}\text { Frequency } \\
\text { N=200 }\end{array}$ & \% \\
\hline Diabetes & 140 & 70 \\
\hline Hypertension & 140 & 70 \\
\hline Coronary heart disease & 112 & 56 \\
\hline
\end{tabular}

Table 3: Health habits of study participants

\begin{tabular}{|l|l|l|}
\hline Item & $\begin{array}{l}\text { Frequency } \\
\text { N=200 }\end{array}$ & \% \\
\hline Fast food consumption & & \\
\hline None & 124 & 62 \\
\hline Once/ week & 48 & 24 \\
\hline Twice/ week & 20 & 10 \\
\hline Three times or more & 8 & 4 \\
\hline Practicing Sport & & \\
\hline Yes & 120 & 60 \\
\hline No & 80 & 40 \\
\hline Frequency of Practicing sports/ week & & \\
\hline Do not practice & 80 & 40 \\
\hline Once & 36 & 18 \\
\hline Twice & 36 & 18 \\
\hline Three times and more & 48 & 24 \\
\hline Smoking Cigarates & & \\
\hline Non-Smokers & 184 & 92 \\
\hline Ex-smokers & 4 & 2 \\
\hline Smokers & 12 & 6 \\
\hline Shisha Smoking & & \\
\hline Yes & 24 & 12 \\
\hline No & 176 & 88 \\
\hline & & \\
\hline
\end{tabular}


Awareness of Hypertension, risk factors and complications among attendants of a Primary Health ..

Table 4: Diagnosis with a chronic disease by Physicians:

\begin{tabular}{|l|l|l|}
\hline Disease & Frequency, N=200 & \% \\
\hline Diabetes & 52 & 26 \\
\hline Hypertension & 24 & 12 \\
\hline Coronary Heart Dis. & 8 & 4 \\
\hline High Cholesterol & 36 & 18 \\
\hline On Regular medications & 56 & 28 \\
\hline
\end{tabular}

Table 5: Knowledge regarding hypertension:

\begin{tabular}{|c|c|c|}
\hline & Frequency, $\mathbf{N}=200$ & $\%$ \\
\hline \multicolumn{3}{|c|}{ Self-evaluation of level of Knowledge } \\
\hline Poor & 136 & 68 \\
\hline Accepted & 24 & 12 \\
\hline Well & 40 & 20 \\
\hline \multicolumn{3}{|c|}{$\begin{array}{l}\text { Normal BP level for an average person with an } \\
\text { age of } 30 \text { years and weight } 70 \mathrm{~kg}\end{array}$} \\
\hline Correct answer & 148 & 74 \\
\hline \multicolumn{3}{|c|}{ Effect of Salt on BP } \\
\hline Correct answer & 180 & 90 \\
\hline \multicolumn{3}{|c|}{ Effect of smoking on BP } \\
\hline Correct answer & 132 & 66 \\
\hline \multicolumn{3}{|c|}{ Diabetes as a risk factor for hypertension } \\
\hline Correct answer & 112 & 56 \\
\hline \multicolumn{3}{|c|}{ Miss-use of oral Contraceptives } \\
\hline Correct answer & 100 & 50 \\
\hline \multicolumn{3}{|c|}{ Psychological stress } \\
\hline Correct answer & 164 & 82 \\
\hline \multicolumn{3}{|l|}{ Obesity } \\
\hline Correct answer & 172 & 86 \\
\hline \multicolumn{3}{|l|}{ Excessive Coffee } \\
\hline Correct answer & 128 & 64 \\
\hline \multicolumn{3}{|l|}{ Energy drinks } \\
\hline Correct answer & 148 & 74 \\
\hline \multicolumn{3}{|l|}{ Family History } \\
\hline Correct answer & 168 & 84 \\
\hline \multicolumn{3}{|l|}{ Practicing Sport } \\
\hline Correct answer & 140 & 70 \\
\hline \multicolumn{3}{|c|}{ Hypertension may affect other body organs } \\
\hline Correct answer & 176 & 88 \\
\hline \multicolumn{3}{|c|}{ Organs than can be affected by High BP } \\
\hline Bones & 18 & 18 \\
\hline Eyes & 144 & 72 \\
\hline Ears & 128 & 64 \\
\hline Heart & 164 & 82 \\
\hline Kidneys & 144 & 72 \\
\hline Brain & 168 & 84 \\
\hline \multicolumn{3}{|c|}{ Hypertension is contagious } \\
\hline Correct answer & 168 & 84 \\
\hline \multicolumn{3}{|c|}{ Symptoms of Hypertension } \\
\hline Drowsiness & 160 & 80 \\
\hline Fatigue & 172 & 86 \\
\hline Headache & 184 & 92 \\
\hline \multicolumn{3}{|c|}{ Prevention of Hypertension } \\
\hline Low salt diet & 156 & 78 \\
\hline Practicing sports & 176 & 88 \\
\hline Loss of weight & 20 & 10 \\
\hline Low fat diet & 148 & 74 \\
\hline Healthy life style & 184 & 92 \\
\hline
\end{tabular}

\section{Discussion}

This study was implanted to assess the current situation regarding the awareness of Saudi community regarding hypertension and its risk factors. An observational descriptive approach was used. Study participants were mainly females and this may be explained by the nature of the health center where our study was implanted. This center offers the health care service in the morning time where most of the males are in their work places. However to overcome this point a special question was asked about the presence of chronic diseases among the first degree relatives. Among our study participant smoking was not representing a problem either smoking cigarettes or shisha as the majority were females having low smoking prevalence $[5,6]$. However many population based studies showed an association between smoking and hypertension, that is why this point 
Awareness of Hypertension, risk factors and complications among attendants of a Primary Health ..

may need to be reflected on the level of awareness among our population, similar point was raised by Thuy et.al. 2010 [7]

Relatively high body mass index was observed among study participants $29 \pm 5.86$ and this was in accordance with what was found in similar studies [8]. Hypertension was three folds more in diabetics and significantly more in obese and those who had high levels of total cholesterol, which is in agreement with many studies[8-11].

The relative moderate to high educational level and monthly income was reflected on the level of knowledge as shown from the percentage of correct answers among our study participant and this was in accordance with many studies investigated the same point $[5,10,12]$.

Being on diet was triggered mainly by obesity (40\%) when compared to hypertension which is only (10\%). More effort should be implemented on the importance of diet and low salt intake as an important factor that may affect hypertension among Saudi population.

As shown from table 2; hypertension and diabetes were found to be the highest chronic disease affecting family members of our study participants (70\%) for both followed by coronary hear disease, although Diabetes came first when asking our study participants about chronic diseases diagnosed by physicians followed by high cholesterol and then hypertension came last. This was in accordance with what was found by Al Nozah et.al 2004 [13].Low level of physical exercise and practicing sports represent a problem among our population although in our study sample $40 \%$ only reported no practice similar find was found by Saeed et.al. 2011[8].

Fast food consumption as a risk factor for hypertension[14] represented only $40 \%$ in our study sample and this was in contrary which was found by other study implemented among university students in Saudi Arabia [15], this may be attributed to the difference in the age group as our study sample age group was around 40 s, mean 38.94 \pm 8.7 . When asking our study sample regrading the diagnosis with chronic diseases $26 \%$ reported diabetes mellitus and this is in accordance to was foun by al Nozha et. al, 2004[13], Followed by hypertension with a prevalence of $12 \%$ [5, 15]. Although only $28 \%$ of our study sample were on regular medication, this may be described with the response of those who had chronic diseases who do not exceed one third of our study sample. As shown from table 5, It was noticed almost $70 \%$ evaluate their level of knowledge regarding hypertension however the correct answers received for our questions showed accepted level of knowledge.

\section{Conclusion and Recommendations}

This study showed a prevalence of $26 \%$ for DM and $12 \%$ prevalence of hypertension. Although, two third of our study participants evaluated their level of knowledge as poor it was noticed that the percent who answered the questions measuring level of knowledge regarding predisposing factors, risk factors and prevention of hypertension were considered high.

This denoted success of the health education program directed toward hypertension. This may be considered a follow up study that may help decision makers regarding the progress of health education program provided to the public. Further studies may be indicated to assess strategies and way of delivery of health education messages.

\section{Conflict of interest:}

The author declares that there is no conflict of interest regarding this work and the study is fully sponsored by the investigator.

\section{References}

[1]. Chobanian, A.V., et al., The seventh report of the joint national committee on prevention, detection, evaluation, and treatment of high blood pressure: the JNC 7 report. Jama, 2003. 289(19): p. 2560-2571.

[2]. Sharma, A.K., S. Bhardwaj, and S. Chaturvedi, Predictors of hypertension in an urban Indian population. Indian heart journal, 2005. 58(1): p. 21-27.

[3]. Wilson, P.W., et al., Prediction of coronary heart disease using risk factor categories. Circulation, 1998. 97(18): p. 1837-1847.

[4]. Association, A.D., Treatment of hypertension in adults with diabetes. Diabetes Care, 2003. $26(\mathrm{suppl} 1$ ): $\mathrm{p} . \mathrm{s} 80-\mathrm{s} 82$.

[5]. Al-Nozha, M.M., et al., Hypertension in Saudi Arabia. Saudi medical journal, 2007. 28(1): p. 77-84.

[6]. Al-Nozha, M.M. and A.K. Osman, The prevalence of hypertension in different geographical regions of Saudi Arabia. Annals of Saudi medicine, 1997. 18(5): p. 401-407.

[7]. Thuy, A.B., et al., The association between smoking and hypertension in a population-based sample of Vietnamese men. Journal of hypertension, 2010. 28(2): p. 245-250.

[8]. Saeed, A.A., et al., Prevalence, awareness, treatment, and control of hypertension among Saudi adult population: a national survey. International journal of hypertension, 2011. 2011.

[9]. Salman, R.A. and K.A. Al-Rubeaan, Incidence and risk factors of hypertension among Saudi type 2 diabetes adult patients: an 11year prospective randomized study. Journal of Diabetes and its Complications, 2009. 23(2): p. 95-101.

[10]. Longo, G.Z., et al., Prevalence of high blood pressure levels and associated factors among adults in Southern Brazil. Arquivos brasileiros de cardiologia, 2009. 93(4): p. 387-394.

[11]. Masala, G., et al., Anthropometric and dietary determinants of blood pressure in over 7000 Mediterranean women: the European Prospective Investigation into Cancer and Nutrition-Florence cohort. Journal of hypertension, 2008. 26(11): p. 2112-2120. 
Awareness of Hypertension, risk factors and complications among attendants of a Primary Health ..

[12]. Kearney, P.M., et al., Global burden of hypertension: analysis of worldwide data. The lancet, 2005. 365(9455): p. 217-223.

[13]. Al-Nozha, M.M., et al., Diabetes mellitus in saudi arabia. 2004.

[14]. Morland, K., A.V.D. Roux, and S. Wing, Supermarkets, other food stores, and obesity: the atherosclerosis risk in communities study. American journal of preventive medicine, 2006. 30(4): p. 333-339.

[15]. Farghaly, N.F., et al., Life style and nutrition and their impact on health of Saudi school students in Abha, Southwestern region of Saudi Arabia. Saudi medical journal, 2007. 28(3): p. 415-421. 